\title{
Welcome to the 15th volume of Future Oncology
}

\author{
Rachel Jenkins*,1 \\ ${ }^{1}$ Future Science Group, Unitec House, 2 Albert Place, London N3 1QB, UK \\ *Author for correspondence: r.jenkins@futuremedicine.com
}

First draft submitted: 4 October 2018; Accepted for publication: 4 October 2018; Published online: 14 December 2018

Keywords: biomarkers $\bullet$ cancer $\bullet$ clinical trials $\bullet$ genetics $\bullet$ immunotherapy $\bullet$ oncology $\bullet$ personalized therapy $\bullet$ research $\bullet$ social media

To all our readers, we are delighted to welcome you to the 15th volume of Future Oncology. The year 2018 was another exciting year for the journal with the continued publication of timely, high quality manuscripts. We are proud to present some of our content highlights within this article.

We would also like to take this opportunity to thank all of our valued Editorial Board members, readers and contributors for their continued support. As we move into 2019, we very much look forward to seeing the journals' continuous progression and development.

\section{Content highlights of 2018}

At the time of writing (October 2018), our most read article was a review entitled 'Optimizing outcomes in EGFR mutation-positive NSCLC: which tyrosine kinase inhibitor and when?' which was paired with an informative video abstract $[1,2]$. The paper was authored by Nicolas Girard from the University of Lyon (France), who discusses the treatment sequencing needed to optimize outcomes in EGFR mutation-positive non-small-cell lung cancer.

Another one of our most popular articles was a review entitled 'Bevacizumab biosimilars: scientific justification for extrapolation of indications' which considers the evidence required to demonstrate biosimilarity for bevacizumab biosimilars, with particular focus on the rationale for extrapolation across oncologic indications [3].

Also highly read was another review investigating the available evidence on the utility of clinical characteristics in the selection of patients with advanced non-small-cell lung cancer as potential candidates for single-agent antiPD-1/PD-L1 therapy, and providing practical guidance to clinicians on identifying those patients who are most likely to benefit [4].

Another highly read article reviewed the clinical value of trifluridine/tipiracil as a monotherapy, including recent trials in gastrointestinal (GI) cancers, and the potential benefit of combining it with other agents in patients with GI cancers [5]. The authors also discussed the emerging strategy for the management of GI cancers in a video abstract [6].

Special mention goes to the following articles, which have achieved the highest Altmetric scores in the journal during 2018, as we continue our successful partnership with the platform:

- Our highest scores were for the drug evaluation 'Aldoxorubicin therapy for the treatment of patients with advanced soft tissue sarcoma' and the previously mentioned review 'Optimizing outcomes in EGFR mutation-positive NSCLC: which tyrosine kinase inhibitor and when?' [1,7]. Altmetric scores: 59 and 28, respectively;

- Another previously mentioned review that scored highly was an article by Peeters and colleagues 'Trifluridine/tipiracil: an emerging strategy for the management of GI cancers' [5] - Altmetric score: 24;

- We also received high scores for a research article discussing the 'Hydration requirements with emetogenic chemotherapy: granisetron extended-release subcutaneous versus palonosetron' [8] - Altmetric score: 18.

\section{Readership demographics}

It is great to see that in 2018, our journal is being read throughout the world, with the highest number of readers being from the North America (35\%), Asia (31\%) and Europe (28\%) (Figure 1). It is great to see an increase in

Future Medicine 

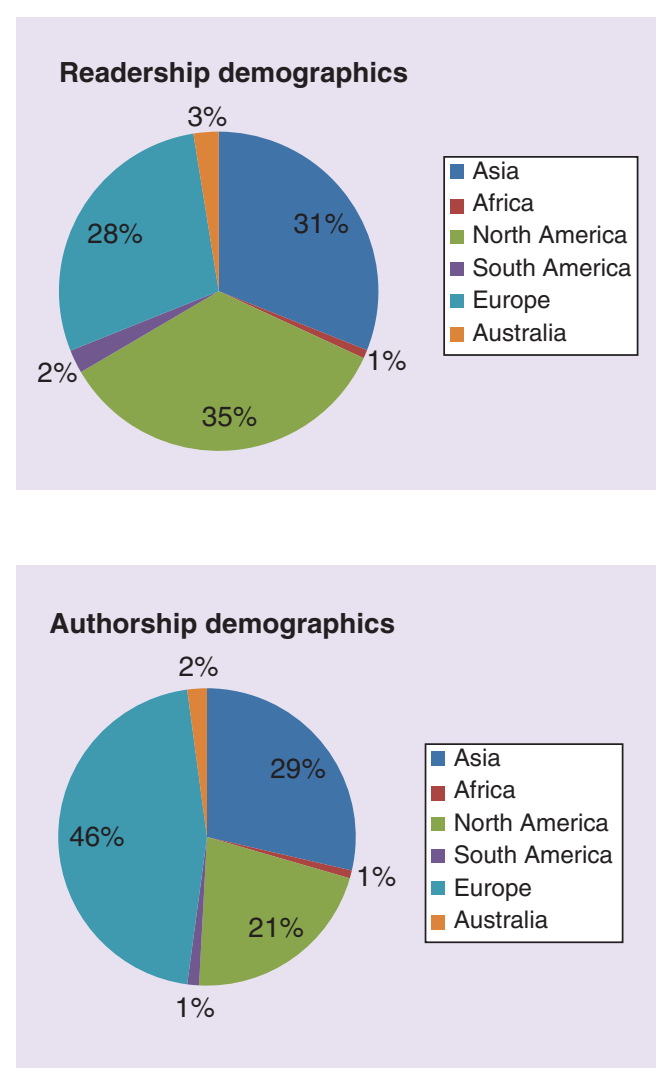

Figure 1. Proportion of readership demographics for Future Oncology in 2018.
Figure 2. Proportion of authorship demographics for Future Oncology in 2018.

readers from Australia in comparison to 2017 from 1 to 3\%.

\section{Authorship demographics}

It is interesting to see where the journal is receiving its content from; in 2018, authors from Europe submitted the highest volume of content (46\%), followed by Asia (29\%) (Figure 2). In terms of countries, the highest numbers of submissions were received from China, USA and Italy. We continue to receive high-quality content from across the globe, including an emerging authorship in Africa and South America.

\section{Social media}

Future Oncology continues to be active across social media including on our Linkedin Future Science Oncology Group [9] and Twitter, @fsgfon [10]. Our regular posts include journal highlights such as newly published content and the latest oncology news. This year, we have thoroughly enjoyed engaging with oncology professionals across the field using a variety of materials including infographics, graphical and video abstracts. We welcome readers to connect with us on various forms of social media going into 2019.

\section{Conclusion}

We appreciate all feedback from the oncology community regarding the direction of our content such as 'hot topics' in the field and trends that you feel should be covered in Future Oncology. We welcome unsolicited article proposals, and would be delighted to hear from you. In particular, we encourage submissions on novel and translational work such as:

- Selective and 'personalized' approaches;

- Immunotherapy;

- Big data and emerging technologies;

- Integration of diagnostic and therapeutic approaches;

- Profiles of new anticancer drugs;

- Biological processes involved in cancer and how new understanding will impact treatment; 
- Clinical implications and applications for new biomarkers;

- Screening programs and methodology;

- Impact of molecular genetics on prevention, screening, diagnosis and treatment.

We greatly look forward to collaborating with you all over the next year and hope Future Oncology continues to fulfill its role in the medical community and grow and develop as a journal.

Financial \& competing interests disclosure

$\mathrm{R}$ Jenkins is an employee of Future Medicine Ltd. The author has no other relevant affiliations or financial involvement with any organization or entity with a financial interest in or financial conflict with the subject matter or materials discussed in the manuscript apart from those disclosed.

No writing assistance was utilized in the production of this manuscript.

\section{References}

1. Girard N. Optimizing outcomes in EGFR mutation-positive NSCLC: which tyrosine kinase inhibitor and when? Future Oncol. 14(11), 1117-1132 (2018).

2. Optimizing outcomes in EGFR mutation-positive NSCLC with TKIs. YouTube. (2018). www.youtube.com/watch?v=Uj_FPafEvN4

3. Melosky B, Reardon D, Nixon A, Subramanian J, Bair A, Jacobs I. Bevacizumab biosimilars: scientific justification for extrapolation of indications. Future Oncol. 14(24), 2507-2520 (2018).

4. Califano R, Lal R, Lewanski C, et al. Patient selection for anti-PD-1/PD-L1 therapy in advanced non-small-cell lung cancer: implications for clinical practice. Future Oncol. 14(23), 2415-2431 (2018).

5. Peeters M, Cervantes A, Moreno Vera S, Taieb J. Trifluridine/tipiracil: an emerging strategy for the management of gastrointestinal cancers. Future Oncol. 14(16), 1629-1645 (2018).

6. Trifluridine/tipiracil: an emerging strategy for the management of gastrointestinal cancers. YouTube. (2018).www.youtube.com/watch?v=WS912JuNo_w

7. Seetharam M, Kolla K, Ganjoo K. Aldoxorubicin therapy for the treatment of patients with advanced soft tissue sarcoma. Future Oncol. 14(23), 2323-2333 (2018).

8. Vacirca J, Caruana D, Mosier M, Boccia R, McBride A. Hydration requirements with emetogenic chemotherapy: granisetron extended-release subcutaneous versus palonosetron. Future Oncol. 14(14), 1387-1396 (2018).

9. LinkedIn. Linkedin.com. (2018). www.linkedin.com/groups/8234713/

10. Future Oncology (@fsgfon) on Twitter. Twitter.com. (2018). https://twitter.com/fsgfon 
